\title{
PRODUTIVIDADE DO MELOEIRO SOB DIFERENTES INTERVALOS DE IRRIGAÇÃO E DISPOSIÇÕES DE LINHAS LATERAIS DE GOTEJAMENTO EM SOLO ARENOSO COESO ${ }^{1}$
}

\author{
Eugênio Ferreira Coelho², Valdemicio Ferreira de Sousa ${ }^{3}$, Bráz Henrique Nunes Rodrigues ${ }^{3}$, \\ Valdomiro Aurélio Barbosa de $\operatorname{Souza}^{4} \&$ Camilo de Lélis Texeira de Andrade
}

\begin{abstract}
RESUMO
Este trabalho, objetiva oferecer alternativas de redução nos custos de sistemas de irrigação por gotejamento do meloeiro, sem afetar o manejo da irrigação e comparar o gotejamento enterrado, em termos de rendimento da cultura, ao gotejamento superficial. $\mathrm{O}$ trabalho foi desenvolvido em um solo arenoso coeso de tabuleiro costeiro, com o delineamento experimental em blocos ao acaso, em parcelas subsubdivididas, com cinco repetições. Os tratamentos consistiram da combinação de quatro intervalos de irrigação (1, 2, 3 e 4 dias) com as linhas laterais de gotejamento junto à fileira de plantas e entre fileiras alternadas de plantas, superficial e enterradas a profundidade de $0,25 \mathrm{~m}$. O intervalo de irrigação e a disposição das linhas laterais não afetaram a produtividade do meloeiro.
\end{abstract}

Palavras-chave: gotejamento superficial, gotejamento subterrâneo, manejo de irrigação

\section{MELON YIELD UNDER DIFFERENT IRRIGATION INTERVALS AND PLACEMENT OF DRIP LINES IN COHESIVE SANDY SOILS}

\begin{abstract}
The research had as its objective the provision of alternatives to reduce costs of drip irrigation systems without affecting the irrigation management and to compare subsurface drip to surface drip in terms of crop yield. The experiment was carried out in a cohesive sand from coastal tablelands. The experiment followed a split-split plot design, in random blocks, with five replications. The treatments consisted of a combination of four irrigation intervals $(1,2,3$ and 4 days) with drip lines in crop rows and drip lines between alternate rows on surface drip line and buried at $0.25 \mathrm{~m}$. The irrigation intervals and drip line location in crop rows did not affect melon yields.
\end{abstract}

Key words: surface drip, subsurface drip, irrigation management

\footnotetext{
${ }^{1}$ Trabalho financiado pela FUNDECI/ETENE, Banco do Nordeste do Brasil - BNB

${ }^{2}$ Eng. Agric., Ph.D., Embrapa Mandioca e Fruticultura, CEP 44380 - 000, Cruz das Almas, BA, Fone: (075) 7212120 , Fax: (075) 721 2149, E-mail: ecoelho@ccnpmf.embrapa.br

${ }^{3}$ Eng. Agric., M.Sc., Embrapa Meio-Norte, CP 01, CEP 64006 - 220, Teresina, PI, Fone: (086) 225 1142, Fax: (086) 225 1141, E-mail: braz@triade.com.br

${ }^{4}$ Eng. Agron., Ph.D., Embrapa Meio-Norte, CP 01, CEP 64006 - 220, Teresina, PI, Fone: (086) 225 1142, Fax: (086) 225 1141, E-mail: valdo@cpamn.embrapa.br

${ }^{5}$ Eng. Agric., Ph.D., Embrapa - Milho e Sorgo, km 24 - BR 48, CEP 37500 - 000, Sete Lagoas, MG, Fone: (031) 779 1000, Fax: (031) 779 1088, E-mail camilo@cnpms.embrapa.br
} 


\section{INTRODUÇÃO}

A elaboração de um projeto de irrigação por gotejamento, deve ter, como base, três objetivos (Burt, 1986): (i) obter um sistema de alta eficiência por meio de alta uniformidade de emissão; (ii) obter um sistema flexível o suficiente para permitir adequado manejo da irrigação e, assim, atender às necessidades hídricas da cultura; e (iii) minimizar os custos fixos anuais. Esses custos são função dos custos iniciais de manutenção e de operação, da água e da energia (Anshutz, 1986).

No caso da irrigação por gotejamento, a minimização dos custos anuais tem sido o ponto de maior atenção dos produtores, pois este método de irrigação localizada tem sido considerado um dos mais onerosos entre os métodos disponíveis. As inovações introduzidas nos últimos anos contribuíram muito para o desenvolvimento de sistemas de irrigação por gotejamento de alta precisão e eficiência (Bucks \& Davis, 1986); entretanto, essas inovações trouxeram também o aumento do custo inicial desses sistemas (Anshutz, 1986).

As pesquisas relativas à engenharia de irrigação, particularmente as referentes a sistemas de irrigação localizada, têm sido dirigidas para o aprimoramento de emissores e válvulas, no sentido de otimizar a uniformidade de emissão, atuando principalmente na redução de entupimento e na compensação da pressão na linha lateral. Uma limitação na adoção do gotejamento para culturas de alto retorno econômico e de alta densidade de plantio, tem sido a necessidade de uso do elevado número de linhas laterais e de gotejadores, que aumenta significativamente os custos desse sistema, porém técnicas alternativas de manejo da irrigação em interação com o sistema podem ser propostas, de forma a reduzir custos, sem diminuir a eficiência de irrigação.

$\mathrm{O}$ uso de sistema de gotejamento enterrado tem-se popularizado no mundo, a medida que os problemas principais citados por Goldberg et al. (1976) ou seja, difícil inspeção, entupimento por raízes ou precipitados e dificuldade de manutenção, tem sido resolvidos pela melhoria dos próprios equipamentos e pela orientação técnica adequada (Phene et al., 1983; Bucks \& Davis, 1986; Phene et al., 1987). No Brasil, tal sistema vem sendo aplicado para culturas de alto retorno econômico, como fruteiras e hortaliças; entretanto, não há literatura sobre avaliação das produtividades de culturas nessas condições. As vantagens principais esperadas com o uso desse sistema, são: eliminação da exposição das linhas laterais aos tratos culturais manuais ou mecânicos, aumento da eficiência da irrigação devido a redução da evaporação e aumento da eficiência de aplicação de fertilizantes via água (Phene et al., 1993). Essas vantagens, juntamente com o incremento de produtividade, devem superar as desvantagens do sistema, entre as quais o custo inicial elevado e os problemas de entupimento e de intrusão de raízes.

O método de irrigação localizada por gotejamento tem sido considerado o mais adequado à cultura do meloeiro pelas condições hídricas, propícias ao desenvolvimento e produção da cultura, que proporcionam ao solo (Goldberg \& Shmueli, 1970; Shmueli \& Goldberg, 1971; Olitta et al., 1978) bem como pelas condições microclimáticas do dossel vegetal menos favoráveis à proliferação de doenças. No Nordeste brasileiro, responsável por $82 \%$ da produção nacional de melão (AGRIANUAL, 1998) grande parte dos plantios são irrigados por gotejamento, cujas produtividades comerciais podem variar de 30 a $45 \mathrm{t} \mathrm{ha}^{-1}$, sob manejo tecnológico adequado (Sousa, 1993; Pinto et al., 1996). Os sistemas de gotejamento usados nessa cultura têm sido projetados para funcionar com uma linha lateral de irrigação por fileira de plantas e as linhas têm sido dispostas na superfície do solo.

O trabalho teve como objetivo: (i) apresentar alternativas para minimizar os custos do sistema de irrigação por gotejamento, sem reduzir a eficiência e a qualidade do manejo da irrigação, por meio do uso de linhas laterais alternadas entre fileiras de culturas; (ii) avaliar o uso do gotejamento enterrado, em termos de rendimento da cultura do meloeiro, em comparação ao gotejamento superficial em solo arenoso coeso de tabuleiro costeiro.

\section{MATERIAL E MÉTODOS}

Este trabalho foi conduzido na área experimental da Embrapa Meio-Norte, em Parnaíba, PI ( $3^{\circ} 5^{\prime} \mathrm{S}$ e $41^{\circ} 47^{\prime} \mathrm{W}$ ) no período de $31 / 10 / 97$ a 10/01/98. O clima da região é equatorial marítimo, com temperatura média anual de $27^{\circ} \mathrm{C}$, umidade relativa média do ar de $75 \%$ e precipitação anual entre 1000 e $1600 \mathrm{~mm}$, concentrada no período janeiro-junho (EMBRAPA, 1992). O solo pertence aos tabuleiros costeiros (Formação Barreiras do Terciário) classificado como areia franca, cujas características físico-hídricas são apresentadas na Tabela 1. Na Figura 1 são apresentadas as características de retenção de água do solo, com base nos valores médios dos teores de água das três camadas amostradas no perfil, ajustados ao modelo não linear de van Genuchten (1980).

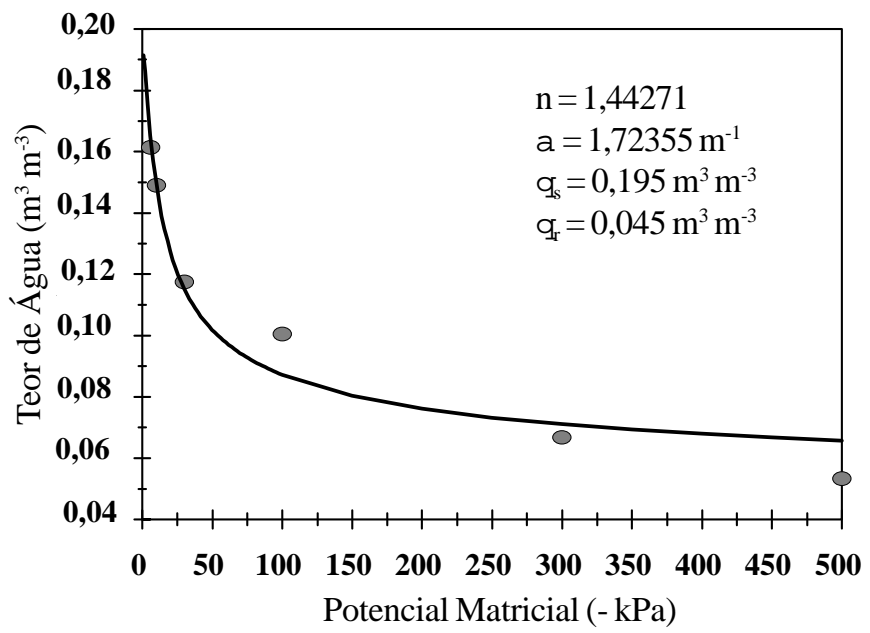

Figura 1. Curva de retenção de água do solo da área experimental $\left(\mathrm{q}_{s}\right.$ - teor de água do solo à saturação, $\mathrm{q}_{\mathrm{r}}$ - teor de água residual do solo)

Tabela 1. Características físico-hídricas do solo da área experimental

\begin{tabular}{|c|c|c|c|c|c|c|c|}
\hline \multirow{2}{*}{$\begin{array}{c}\text { Profundidade } \\
\text { (m) }\end{array}$} & \multirow{2}{*}{$\begin{array}{l}\text { Areia } \\
\text { grossa }\end{array}$} & \multirow{2}{*}{$\begin{array}{c}\text { Areia } \\
\text { fina }\end{array}$} & \multirow[t]{2}{*}{ Silte } & \multirow[t]{2}{*}{ Argila } & \multicolumn{2}{|c|}{ Densidade } & \multirow{2}{*}{$\begin{array}{c}\text { Porosidade } \\
\text { total } \\
\mathrm{m}^{3} \mathrm{~m}^{-3}\end{array}$} \\
\hline & & & & & $\begin{array}{l}\text { Aparente } \\
\end{array}$ & $\begin{array}{l}\text { Partículas } \\
-3 \text { ) }\end{array}$ & \\
\hline $0,00-0,15$ & 500 & 380 & 20 & 100 & 1,65 & 2,63 & 0,3713 \\
\hline $0,15-0,30$ & 480 & 400 & 30 & 80 & 1,75 & 2,68 & 0,3449 \\
\hline $0,30-0,45$ & 460 & 370 & 40 & 130 & 1,74 & 2,68 & 0,3485 \\
\hline
\end{tabular}


A área experimental de $1920 \mathrm{~m}^{2}$ foi dividida em cinco blocos de $16 \times 24 \mathrm{~m}$ e estes em quatro parcelas de $16 \times 6 \mathrm{~m}$; cada parcela foi constituída de duas subparcelas de $8 \times 6 \mathrm{~m}$, e cada subparcela de duas subsubparcelas de $4 \times 6 \mathrm{~m}$. Foi utilizada a cultivar de melão Gold Mine, plantada no espaçamento de $1,50 \times 0,30 \mathrm{~m}$ (população de 22.222 plantas ha $^{-1}$ ).

O experimento foi conduzido no delineamento experimental em blocos ao acaso, arranjado em parcelas subsubdivididas, com cinco repetições. Os tratamentos estudados foram: (i) na parcela, quatro intervalos de irrigação (1, 2, 3 e 4 dias); (ii) na subparcela, duas disposições das linhas laterais (uma junto à fileira de plantas e outra entre fileiras alternadas de plantas); (iii) na subsubparcela, dois níveis de disposição do sistema de irrigação (gotejamento superficial e gotejamento enterrado a $0,25 \mathrm{~m}$ de profundidade). Cada subsubparcela teve área útil de $8,1 \mathrm{~m}^{2}$ e 18 plantas.

Utilizou-se um sistema de irrigação por gotejamento, com linhas laterais de $17 \mathrm{~mm}$ de diâmetro externo, com gotejadores "na linha" do tipo labirinto, autocompensantes e autolimpantes, vazão $2 \mathrm{~L} \mathrm{~h}^{-1}$ e espaçados de $0,5 \mathrm{~m}$. A quantidade de água aplicada por irrigação foi definida pelo balanço de água do solo, sendo a evapotranspiração da cultura determinada pela evapotranspiração de referência obtida da evaporação do tanque Classe "A" e pelo coeficiente de cultivo da cultura (Doorenbos \& Kassam, 1979). Nos 13 dias iniciais do ciclo da cultura, a irrigação das subsubparcelas com gotejamento enterrado e das parcelas com linhas laterais entre fileiras de plantas, foi feita por microaspersão o que, em condições práticas, poderia ser realizado por um sistema de aspersão convencional portátil, que atenderia, além do meloeiro, a outras culturas da fazenda. Esta irrigação por aspersão, em caso de falta de precipitação pluviométrica no período, é necessária para a emergência das plântulas, formação e desenvolvimento do sistema radicular o suficiente para atingir o bulbo molhado.

O monitoramento da água no solo foi feito durante as fases de desenvolvimento vegetativo, floração e frutificação da cultura. Utilizou-se uma sonda de neutrons, com leituras a 0,25 e $0,50 \mathrm{~m}$ de profundidade e a $0,05 \mathrm{~m}$ do gotejador; foi também monitorado, nos mesmos estágios de desenvolvimento da cultura, o teor de água do solo por meio de gravimetria, utilizando-se amostras de solo coletadas em 30 posições diferentes de uma malha retangular, conforme ilustrado na Figura 2. As amostras foram coletadas antes das irrigações, $2 \mathrm{~h}$ e 24 $\mathrm{h}$ após, para intervalos de irrigação de 1 e 2 dias. Os teores de água determinados na malha permitiram definir o domínio do volume molhado, com base nos valores em todas as posições, antes e após as irrigações.

A adubação nitrogenada foi efetuada via água de irrigação, aplicando-se $120 \mathrm{~kg}$ de $\mathrm{N} \mathrm{ha}^{-1}$. Para a adubação potássica, utilizaram-se $130 \mathrm{~kg}$ de $\mathrm{K}_{2} \mathrm{O} \mathrm{ha}^{-1}$, sendo $1 / 3$ aplicado no solo e $2 / 3$ via água de irrigação. O fósforo e os micronutrientes foram aplicados nas quantidades sugeridas por Pinto et al. (1996).

A distribuição de raízes da cultura sob diferentes tratamentos foi determinada na mesma malha mostrada na Figura 2. As amostras foram coletadas nos estádios de desenvolvimento vegetativo, floração e frutificação da cultura, por monolitos e processadas por lavagem e separação das raízes (Böhm, 1979). Posteriormente, foram obtidas imagens digitais das raízes determinando-se a densidade de comprimento das raízes com uso do aplicativo Rootedge (Kaspar \& Ewing, 1997).

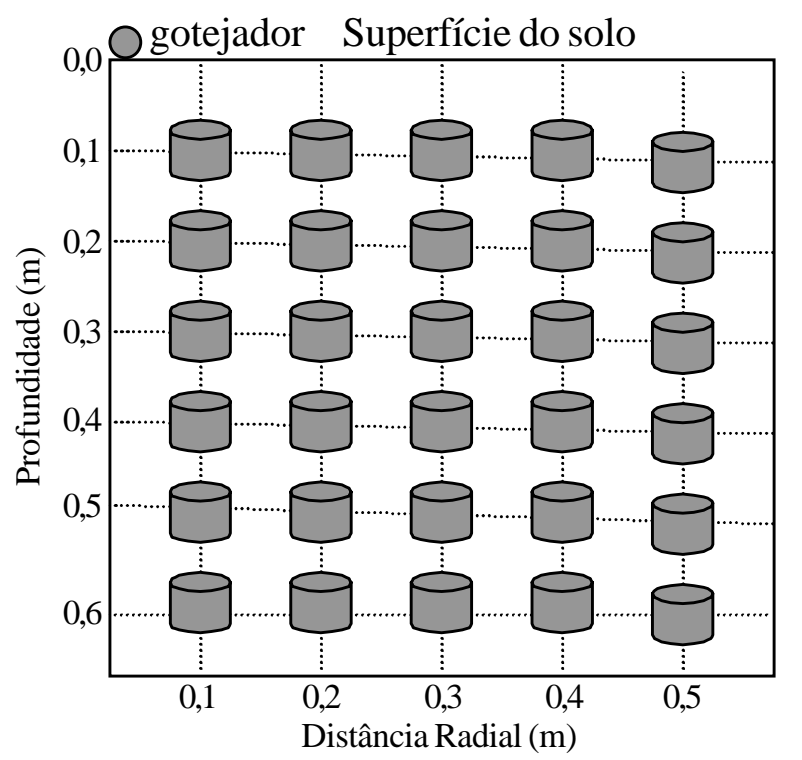

Figura 2. Posições de coleta de amostras de solo para determinação do teor de água do solo e densidade de comprimento de raízes

Foram realizadas três colheitas, onde as produtividades total e comercial da cultura foram avaliadas por meio de análise estatística sendo que a produtividade comercial baseou-se em frutos de peso igual ou superior a $0,800 \mathrm{~kg}$.

\section{RESULTADOS E DISCUSSÃO}

\section{Intervalos de irrigação e disposição das linhas laterais}

Não houve diferença significativa $(p>0,05)$ entre intervalos de irrigação para as produtividades médias total e comercial (Tabela 2). Esses resultados divergiram dos obtidos sob as mesmas condições edafoclimáticas, por Sousa et al. (1998) ao testarem diferentes intervalos de irrigação por gotejamento superficial com as linhas de irrigação junto às fileiras de plantas de meloeiro (Eldorado 300) cujas produtividades total e comercial para intervalos de irrigação de um e dois dias foram superiores às obtidas para os intervalos de três e quatro dias.

Tabela 2. Médias de produtividade total e comercial do meloeiro em diferentes intervalos de irrigação

\begin{tabular}{|c|c|c|}
\hline \multirow{2}{*}{$\begin{array}{l}\text { Intervalo de } \\
\text { Irrigação } \\
\text { (dias) }\end{array}$} & \multicolumn{2}{|c|}{ Produtividade $^{*}$} \\
\hline & Total & Comercial \\
\hline 2 & 39,68 & 39,63 \\
\hline 4 & 38,45 & 38,40 \\
\hline 3 & 38,41 & 36,92 \\
\hline 1 & 35,85 & 35,79 \\
\hline Média & 38,10 & 37,69 \\
\hline C.V (\%) & 12,97 & 17,47 \\
\hline
\end{tabular}


As produtividades total e comercial do meloeiro não dependeram da disposição das linhas laterais em relação às fileiras de plantas (Tabela 3) isto é, não houve interação entre o intervalo de irrigação e a disposição das linhas de gotejamento em relação às fileiras de plantas; contudo, os resultados dão suporte à hipótese de que o aumento do intervalo de irrigação pode compensar o aumento do espaçamento entre linhas laterais, porque a lâmina aplicada é maior para intervalos maiores; em conseqüência, o movimento lateral de água torna-se mais acentuado (Figura 3) resultando em maior e mais achatado volume molhado. Conforme Sousa \& Coelho (no prelo) para o solo em estudo com gotejadores na superfície, o diâmetro molhado pode atingir 0,70 e 0,84 m quando se aplica 20 e $30 \mathrm{~L}$ de água, respectivamente. Essa distribuição de água favorece a migração das raízes da região da fileira de plantas para o volume molhado, no caso das linhas de gotejamento entre fileiras de plantas.

Tabela 3. Médias de produtividade total e produtividade comercial do meloeiro sob duas disposições das linhas laterais de gotejadores

\begin{tabular}{|c|c|c|}
\hline \multirow{2}{*}{$\begin{array}{c}\text { Disposição } \\
\text { da linha } \\
\text { lateral }\end{array}$} & \multicolumn{2}{|c|}{ Produtividade $^{*}$} \\
\hline & Total & Comercial \\
\hline $\mathrm{Na}$ fileira & 38,98 & 38,96 \\
\hline Entre fileiras & 37,23 & 36,42 \\
\hline Média & 38,10 & 37,69 \\
\hline C.V. (\%) & 12,97 & 17,47 \\
\hline
\end{tabular}

* Teste $\mathrm{F}$ não significativo $(\mathrm{p}>0,05)$

A migração das raízes pode ser constatada observando-se a Figura 4, que mostra o deslocamento do centro de densidade de comprimento das raízes, onde provavelmente ocorre a maior absorção de água, para a região do bulbo molhado no sentido do gotejador, para 3 e 4 dias de intervalo de irrigação, com as linhas de gotejamento entre fileiras alternadas de plantas. Os teores médios de água, durante o estágio de floração, obtidos a $0,25 \mathrm{~m}$ de profundidade, antes, 24 e $48 \mathrm{~h}$ após a irrigação (Tabela 4) demonstram redução do teor de água, no final do ciclo de irrigação, crescente com o aumento do intervalo de irrigação mas, devido à compensação na lâmina aplicada, os teores de água durante parte do ciclo de irrigação ( 24 h após a irrigação) apresentaram valores próximos ou acima do limite superior da disponibilidade de água.

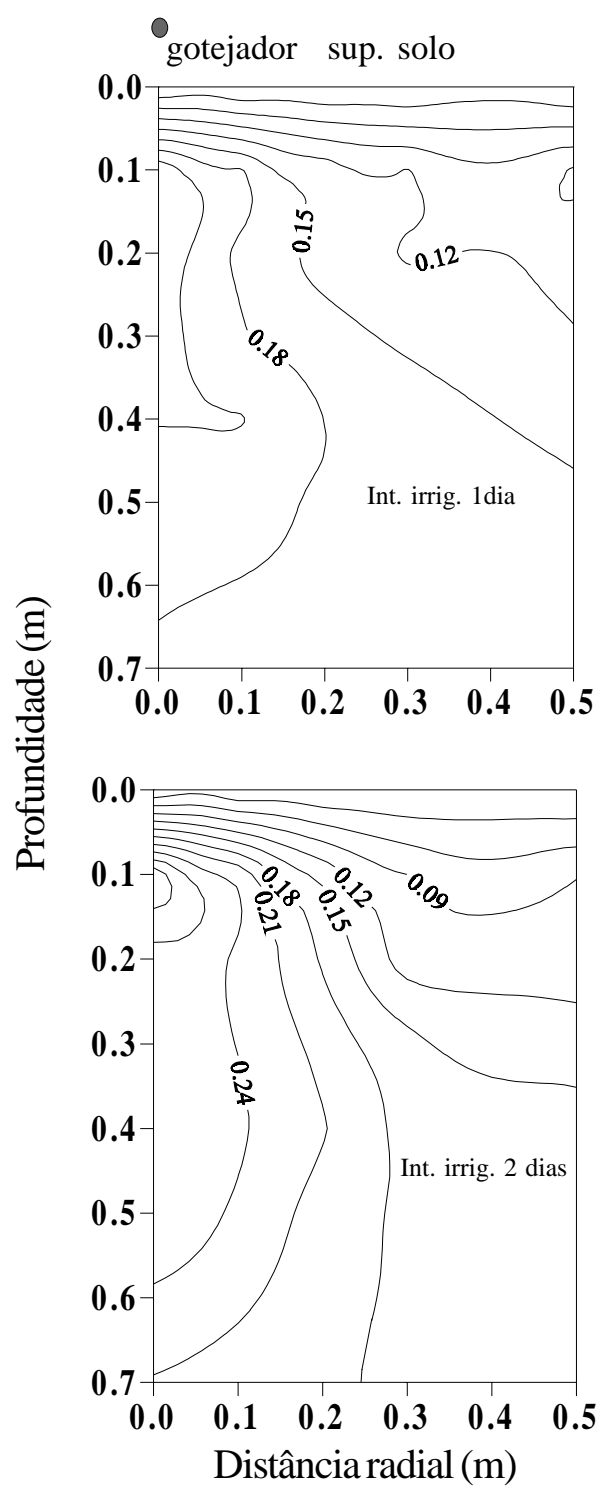

Figura 3. Isolinhas do teor de água do solo $\left(\mathrm{m}^{3} \mathrm{~m}^{-3}\right)$ em relação ao gotejador, $2 \mathrm{~h}$ após a irrigação, sob os intervalos entre irrigações de 1 e 2 dias

O menor valor de produtividade média para o intervalo de um dia entre irrigações (Tabela 2) foi devido, principalmente, às produtividades do tratamento referente às linhas de gotejamento entre fileiras alternadas de plantas. Neste caso, as irrigações diárias representaram a menor lâmina por irrigação,

Tabela 4. Teores médios de água do solo $\left(\mathrm{m}^{3} \mathrm{~m}^{-3}\right)$ determinados pela sonda de nêutrons junto ao gotejador à profundidade $0,25 \mathrm{~m}$ para disposição da linha de gotejamento na fileira de plantas e entre fileira de plantas em dois ciclos de irrigação no estádio de floração do meloeiro

\begin{tabular}{ccccc}
\hline $\begin{array}{c}\text { Disposição da Linha } \\
\text { Lateral }\end{array}$ & $\begin{array}{c}\text { Intervalo de Irrigação } \\
\text { (dias) }\end{array}$ & $\begin{array}{c}\text { Antes da } \\
\text { Irrigação }\end{array}$ & $\begin{array}{c}\text { 24 h Após } \\
\text { a Irrigação }\end{array}$ & $\begin{array}{c}\text { 48 h Após } \\
\text { a Irrigação }\end{array}$ \\
\hline \multirow{3}{*}{ Na fileira } & 1 & 0,170 & 0,215 & 0,175 \\
& 2 & 0,158 & 0,205 & 0,164 \\
& 3 & 0,123 & 0,190 & - \\
Entre fileiras & 4 & 0,140 & 0,161 & 0,150 \\
\hline & 1 & 0,166 & 0,215 & 0,164 \\
& 2 & 0,140 & 0,173 & 0,130 \\
& 4 & 0,120 & 0,176 & 0,138 \\
\hline
\end{tabular}




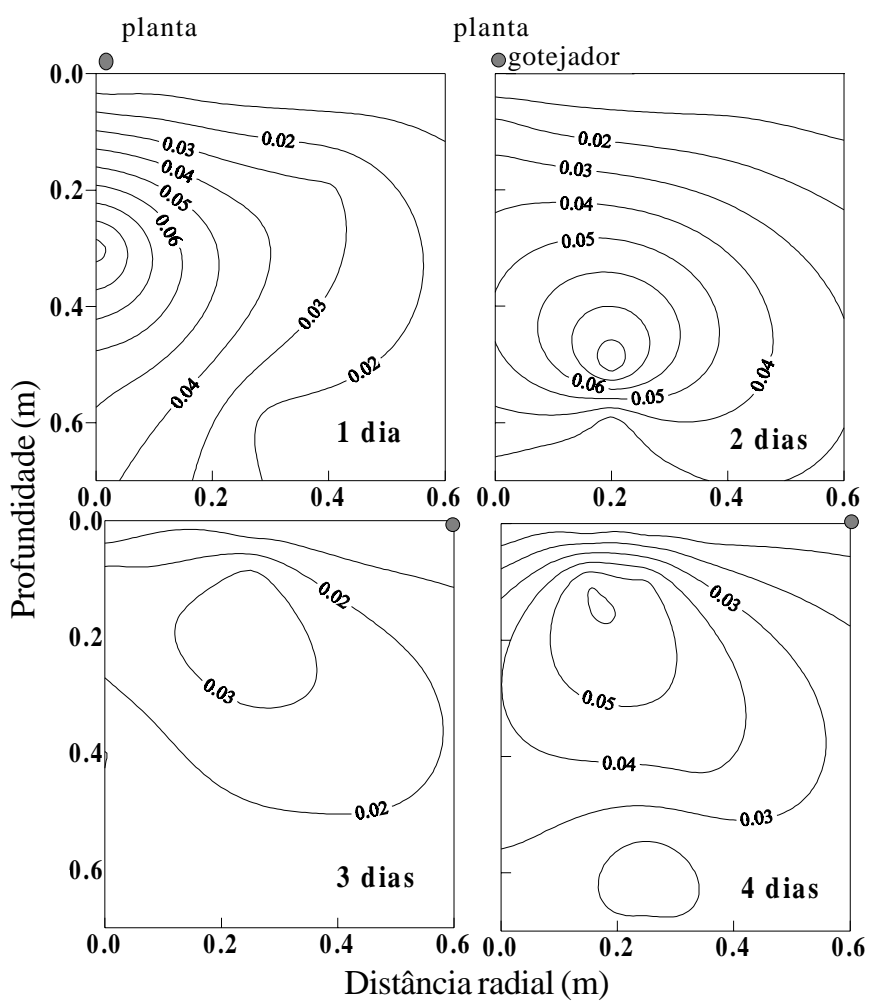

Figura 4. Densidade de comprimento de raízes $\left(\mathrm{cm} \mathrm{cm}^{-3}\right)$ para quatro intervalos de irrigação, gotejador junto à fileira de plantas para intervalos de 1 e 2 dias e entre fileiras para intervalos de 3 e 4 dias

o que resultou numa faixa molhada de menor raio lateral (Figura 3) dificultando, assim, o acesso das raízes das plantas à água retida a menores potenciais nas regiões mais centrais do bulbo molhado.

Na Figura 3, as isolinhas de teores de água, abaixo da região de domínio do sistema radicular ilustrado na Figura 4, indicam a ocorrência de percolação, com maior intensidade para o intervalo de irrigação de dois dias. Apesar da inexistência de dados de teores de água nos perfis correspondentes aos intervalos de irrigação de 3 e 4 dias, provavelmente a perda por percolação foi mais intensa nesses intervalos, principaunente para os tratamentos com linhas de gotejamento entre fileiras de plantas, onde pelo menos em $40 \%$ das irrigações foram aplicados mais de $20 \mathrm{~L}$ de água por gotejador, valor este, suficiente para acarretar percolação no perfil do solo em estudo (Sousa \& Coelho, prelo).

As produtividades similares obtidas para a cultura do melão, independente da disposição das linhas de gotejamento e dos intervalos de irrigação (Tabelas 2 e 3 ) indicam a viabilidade técnica do uso de linhas laterais de gotejamento entre fileiras alternadas de plantas de melão (espaçamento entre linhas de até $3 \mathrm{~m}$ ) ou seja, uma linha de gotejamento para cada duas fileiras de plantas. O intervalo de irrigação de dois dias é o mais adequado a esta disposição de linhas de gotejamento nas condições edafoclimáticas do local do estudo, uma vez que permite a distribuição de água no volume molhado suficiente para atender à demanda hídrica da cultura, com baixo risco de perdas por percolação.

\section{Disposição da linha de gotejamento em relação à superfície do} solo

Não houve diferença significativa entre as produtividades do meloeiro irrigado por gotejamento superficial e enterrado (Tabela 5).

Tabela 5. Efeito de duas posições das linhas laterais (superfícial e enterrada) sob as produtividades total e comercial do meloeiro

\begin{tabular}{cll}
\hline Posição & \multicolumn{2}{c}{ Produtividade } \\
\cline { 2 - 3 } da Linha & \multicolumn{1}{c}{ Total } & Comercial \\
Lateral & & \\
\cline { 2 - 3 }$\left(\mathrm{t} \mathrm{ha}^{-1}\right)$ & \\
\hline Superfície & 38,133 & 38,078 \\
Enterrada & 38,073 & 37,298 \\
\hline Média & 38,10 & 37,69 \\
\hline C.V $(\%)$ & 12,97 & 17,47 \\
* Teste F não significativo $(\mathrm{p}>0,05)$ & &
\end{tabular}

Foi avaliada a distribuição de água num plano, perpendicular à direção da linha lateral, de $0,65 \mathrm{~m}$ de profundidade $\mathrm{x} 0,45 \mathrm{~m}$ de largura $\mathrm{x} 0,01 \mathrm{~m}$ de espessura, similar a da Figura 2 no volume de solo, tanto para o gotejamento enterrado como para o superficial, a partir de 15 determinações de teor de água pelo método gravimétrico nos 30 pontos da malha retangular, ilustrada na Figura 2. O teor médio de água nesses pontos, considerando-se o sistema superficial, foi comparado com o teor médio sob sistema enterrado, pelo teste t. O teor médio $0,1493 \mathrm{~cm}^{3} \mathrm{~cm}^{-3}$, resultante do sistema superficial, não diferiu do teor médio $0,1464 \mathrm{~cm}^{3} \mathrm{~cm}^{-3}$ do sistema enterrado pelo teste $\mathrm{t}(\mathrm{p}>0,05)$.

Considerando-se a geometria esférica e semi-esférica do volume molhado para o gotejamento enterrado e superficial, respectivamente, adotada por Ben-Asher \& Phene (1993) esta proximidade dos teores de água do solo referentes aos dois sistemas de gotejamento, indicaria, teoricamente, um raio do volume molhado no caso do gotejamento enterrado, $20 \%$ inferior ao raio do volume molhado no caso do gotejamento superficial adotado por Ben-Asher \& Phene (1993) o que não foi observado no presente estudo, conforme ilustra a Figura 5.

Esses teores médios próximos entre si, resultantes de valores individuais verificados em diferentes períodos após a irrigação, indicam similaridade na quantidade de água disponível para as plantas no bulbo molhado nos dois sistemas de gotejamento, contribuindo para explicar as produtividades semelhantes obtidas nos dois sistemas.

Esses resultados não colocam o gotejamento enterrado em posição de vantagem em relação ao sistema superficial, em termos de produtividade, conforme preconiza Or (1997). A recomendação de seu uso fica dependente do balanço das vantagens relativas à redução das perdas de linhas laterais decorrentes dos tratos culturais e das desvantagens relativas ao aumento do custo de implantação do sistema que, no mínimo, adiciona a instalação das linhas laterais enterradas.

No caso do melão plantado em condições semi-áridas do Nordeste brasileiro, o uso do gotejamento enterrado, principalmente em solos de textura arenosa, apresenta uma limitação durante o período de germinação das sementes, que é fornecer água aos primeiros centímetros abaixo da superfície do solo onde as sementes são colocadas. Para solos com textura semelhante à do experimento, a 
(A)

(B)

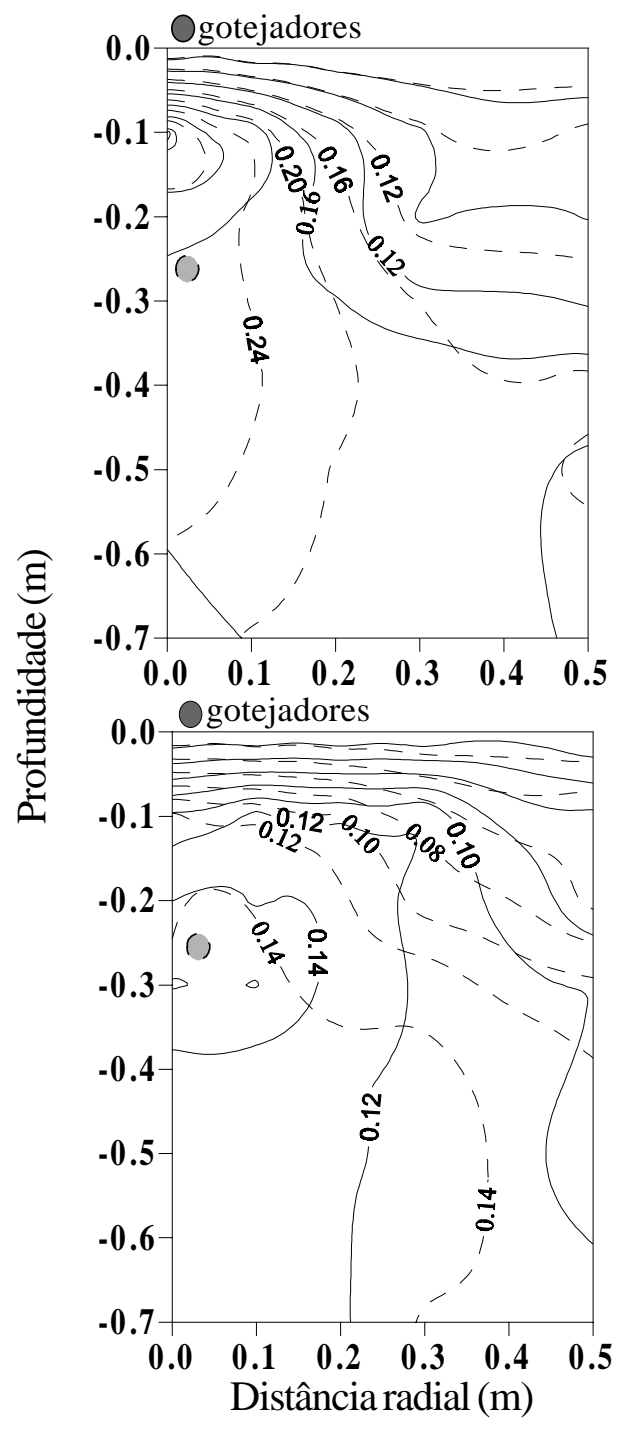

Superficial

Enterrado

Figura 5. Isolinhas do teor de água $\left(\mathrm{m}^{3} \mathrm{~m}^{-3}\right) 2 \mathrm{~h}$ após uma irrigação (A) e antes da próxima irrigação (B) e para os dois sistemas de gotejamento (superficial e enterrado)

profundidade de $0,25 \mathrm{~m}$ das linhas não é suficiente para manter um teor de água adequado a $0,05 \mathrm{~m}$ de profundidade. Assim, foi necessário efetuar-se irrigação por microaspersão no estágio inicial, para permitir a germinação e o desenvolvimento das raízes. Este procedimento é comum em países que utilizam o sistema de irrigação por gotejamento e a limitação pode, no entanto, ser corrigida, em parte, pela instalação das linhas laterais de gotejamento em profundidades que permitam o volume molhado tangenciar a superfície do solo. No caso de plantio por mudas em épocas chuvosas, não ocorre esse problema.

\section{CONCLUSÕES}

1. O uso de linhas laterais de gotejamento entre fileiras alternadas de plantas de melão com o intervalo de irrigação de 2 dias permite produtividades comerciais compatíveis com as obtidas com o uso de uma linha lateral por fileira de plantas para o solo em questão.
2. A recomendação do uso do gotejamento enterrado para o meloeiro em condições semelhantes à desse estudo, depende do balanço entre as vantagens relativas à redução das perdas no sistema, decorrentes dos tratos culturais e das desvantagens relativas ao custo do sistema, uma vez que os rendimentos obtidos com seu uso não diferem dos obtidos com uso do gotejamento superficial.

\section{REFERÊNCIAS BIBLIOGRÁFICAS}

\section{AGRIANUAL 98; ANUÁRIO DA AGRICULTURA} BRASILEIRA. São Paulo: FNP Consultoria \& Comércio/ Mendes \& Scotoni. 1998. 481p.

ANSHUTZ, J.D. Efficient and economical drip irrigation systems designer's considerations. In: ZOLDOSKE, D.F.; MIYASAKI, M.Y. Microirrigations methods and materials update. Fresno: California Agricultural Technology Institute, 1986. p.1-3.

BEN-ASHER, J.; PHENE, C.J. Analysis of surface and subsurface drip irrigation using a numerical model. In: JORGENSEN, G.S.; NORUM, K.N. Subsurface drip irrigation. Theory, practices and application. Fresno: California Center of Irrigation Technology. 1993, p.185-201.

BÖHM, W. Methods of studying root systems. New York: Springer-Verlag, 1979. 194p.

BUCKS, D.A.; DAVIS, S. Introduction. In: NAKAYAMA, F.S.; BUCKS, D.A. eds. Trickle irrigation for crop production, design, operation and management. New York: Elsevier, 1986. p.12-13.

BURT, C. Strategies for high emission uniformity design. In: ZOLDOSKE, D.F.; MIYASAKI, Microirrigations methods and materials update. Fresno: California Agricultural Technology Institute, 1986. p.73-78.

DOORENBOS, J.; KASSAM, A.H. Yield response to water. Rome: FAO, 1979. 139p. FAO Irrigation and Drainage Paper, 33

EMBRAPA. Centro Nacional de Agricultura Irrigada (Parnaíba, PI). Boletim Agrometeorológico. Parnaíba: EMBRAPACNPAI, 1992, 44p. EMBRAPA-CNPAI. Boletim Agrometeorológico, 3

GOLDBERG, D.B.; GORNAT, B.; RIMON, D. Drip irrigation., Kfar Shmaryalu: Drip Irrigation Scientific Publications. 1976. p.10-11.

GOLDBERG, D.B.; SHMUELI, M. Drip irrigation: A method used under arid desert conditions of high water and soil salinity. Transactions of the ASAE, St. Joseph, v.13, p.38-41, 1970.

KASPAR, T. C.; EWING, R.P. Rootedge: Software for measuring root length from desktop scanner images. Agronomy Journal, Madison, v.89, p.932-940. 1997.

OLLITA, A.F.L.; ABREU, T.A.; MARCHETTI, D.A.B. Estudo comparativo dos métodos de irrigação por sulco e gotejo na cultura do melão. Solo, v. 70, n. 2, p. 7-14, 1978.

OR, U. La aplicacion precisa del agua y fertilizante aumenta la producion. Agrotecnologia en Israel, Tel-Aviv, v.1, p.28-33. 1997.

PHENE, C.J.; BLUME, M.F.; HILE, M.M.S.; MEEK,D.W.; RE, J.V. Management of subsurface trickle systems. ASAE paper No. 83-2598, St Joseph, p. 23. 1983. 
PHENE, C.J.; DAVIS, K.R.; HUTMACHER, R.B.; MCCORMICK, R.L. Advantages of subsurface drip irrigation for processing tomatoes. In: INTERNATIONAL SYMPOSIUM ON INTEGRATED MANAGEMENT PRACTICES FOR TOMATO AND PEPPER PRODUCTION IN THE TROPICS, 1987, SHANHUA. Proceedings... 1987, p. 325-338.

PHENE, C.J.; HUTMACHER,R.B.; AYARS, J.E. Subsurface drip irrigation: Realizing the full potential. In: JORGENSEN, G.S.; NORUM, K.N. Subsurface drip irrigation. Theory, practices and application. Fresno: California Center of Irrigation Technology, 1993. p.73-78.

PINTO, J.M.; SOARES, J.M.; PEREIRA, J.R; COSTA, N.D.; BRITO, L.T.L.; FARIA, C.M.B.; MACIEL, J.L. Sistema de cultivo de melão com aplicação de fertilizantes via água de irrigação. Petrolina: EMBRAPA-CPATSA. 1996.24p. Circular Técnica, 36

SHMUELLI, M.; GOLDBERG, S.D. Riego por aspercion, por sulco e por gotejo del melon in una zona arida. Jerusalem: Universidade Hebrea de Jerusalem, 1971. 5p.
SOUSA, V.F. Freqüiência de aplicação de N e K via irrigação por gotejamento no meloeiro (Cucumis melo L.) cv. El Dorado 300 em solo de textura arenosa. Botucatu: UNESP, 1993. Tese Mestrado

SOUSA, V.F.; COELHO, E.F. Dinâmica de água num solo arenoso sob irrigação por gotejamento. Pesquisa Agropecuária Brasileira. Brasília. 1999. (no prelo)

SOUSA, V.F. de; COELHO, E.F.; FRIZZONE, J.A.; FOLEGATTI, M.V.; ANDRADE JUNIOR, A.S.; OLIVEIRA, F. das C. Freqüência de irrigação por gotejamento na eficiência do uso da água no meloeiro. In: CONGRESSO BRASILEIRO DE ENGENHARIA RURAL, 27, 1998, Poços de Caldas. Anais... Poços de Caldas, Sociedade Brasileira de Engenharia Agrícola, 1998. v.1, p.214-16.

van GENUCHTEN, M. Th. A closed-form equation for predicting the hydraulic conductivity of unsaturated soils. Soil Science Society of America Journal , Madison, v. 44, p.892-898. 1980. 